Marquette University

e-Publications@Marquette

Civil and Environmental Engineering Faculty

Civil and Environmental Engineering, Department

Research and Publications

$2-1-2018$

Evaluation of Continuous Monitoring as a Tool for Municipal Stormwater Management Programs

Walter M. McDonald

Marquette University, walter.mcdonald@marquette.edu

Randel L. Dymond

Virginia Tech

Vinod K. Lohani

Virginia Tech

Accepted version. Journal of Sustainable Water in The Built Environment, Vol. 4, No. 1 (February 2018): 04017016. DOI. (C) 2018, American Society of Civil Engineers. Used with permission. 
Marquette University

\section{e-Publications@Marquette}

\section{Civil, Construction, and Environmental Engineering Faculty Research and Publications/College of Engineering}

This paper is NOT THE PUBLISHED VERSION; but the author's final, peer-reviewed manuscript. The published version may be accessed by following the link in the citation below.

Journal of Sustainable Water in the Built Environment, Vol. 4, No. 1 (February, 2018). DOI. This article is (C) American Society of Civil Engineers (ASCE) and permission has been granted for this version to appear in e-Publications@Marquette. ASCE does not grant permission for this article to be further copied/distributed or hosted elsewhere without the express permission from ASCE.

\section{Contents}

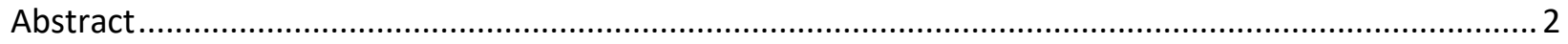

Introduction …

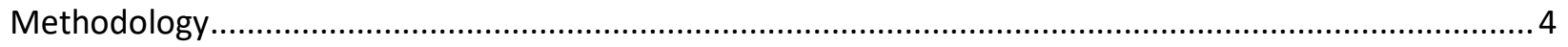

Evaluating Uncertainty Attributable to Inadequate Temporal Sampling ............................................5

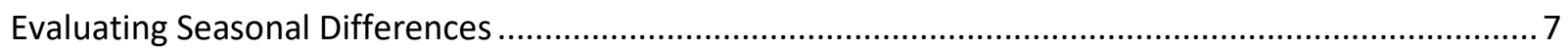

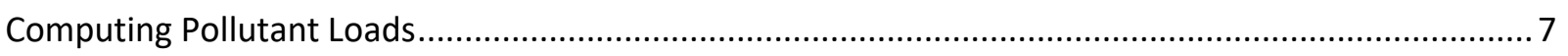

Capturing Acute Toxicity Events and Illicit Discharges ................................................................ 7

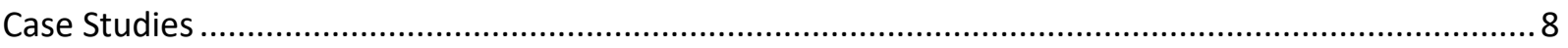

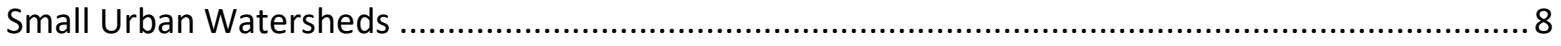

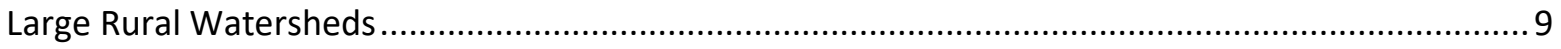

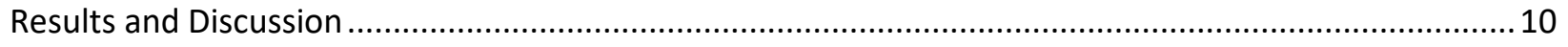

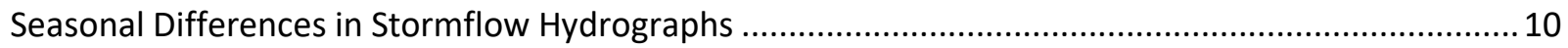

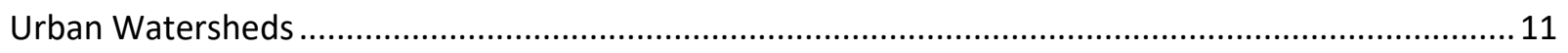

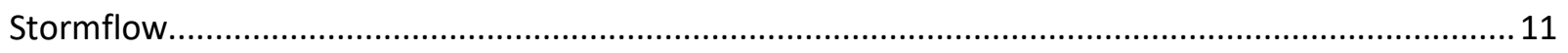

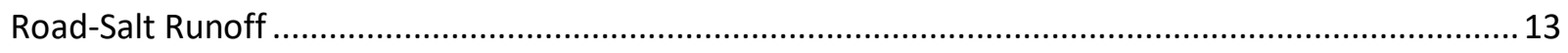

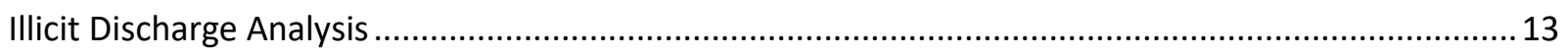


Rural Watersheds

Stormflow.

Storm Event Pollutant Concentrations and Loads

\title{
Evaluation of Continuous Monitoring as a Tool for Municipal Stormwater Management Programs
}

\author{
Walter M. McDonald \\ Department of Civil, Construction and Environmental Engineering, Marquette University, \\ Milwaukee, WI \\ Randel L. Dymond \\ Department of Civil and Environmental Engineering, Virginia Tech University, Blacksburg, VA \\ Vinod K. Lohani \\ Department of Engineering Education; Education \& Global Initiatives, ICTAS, Virginia Tech \\ University, Blacksburg, VA
}

\section{Abstract}

The purpose of this study is to evaluate the uncertainty attributable to inadequate temporal sampling of stormwater discharge and water quality, and understand its implications for meeting monitoring objectives relevant to municipal separate storm sewer systems (MS4s). A methodology is presented to evaluate uncertainty attributable to inadequate temporal sampling of continuous stormflow and water quality, and a case study demonstrates the application of the methodology to six small urban watersheds (0.8-6.8 $\left.\mathrm{km}^{2}\right)$ and six large rural watersheds $\left(30-16,192 \mathrm{~km}^{2}\right)$ in Virginia. Results indicate the necessity of high-frequency continuous monitoring for accurately capturing multiple monitoring objectives, including illicit discharges, acute toxicity events, and stormflow pollutant concentrations and loads, as compared to traditional methods of sampling. For example, 1-h sampling in small urban watersheds and daily sampling in large rural watersheds would introduce uncertainty in capturing pollutant loads of $3-46 \%$ and $10-28 \%$, respectively. Overall, the outcomes from this study highlight how 
MS4s can leverage continuous monitoring to meet multiple objectives under current and future regulatory environments.

\section{Introduction}

Stormwater laws in the United States require states to regulate the water quality of surface water runoff through programs such as the national pollutant discharge elimination system (NPDES) and total maximum daily load (TMDL) programs (Sections 402 and 303d of the Clean Water Act). Municipal separate storm sewer systems (MS4s) are a specific entity regulated under the NPDES and TMDL programs as point-source pollutants. Pollution that occurs from diffuse rainfall-runoff processes is typically thought of as non-point-source pollution; however, the federal regulatory programs view stormwater runoff as point-source pollution because it enters waters of the state through pipes and channels at specific locations. The NPDES stormwater program requires MS4s to obtain permits for their point-source stormwater outfall discharges by implementing stormwater management programs that document the stormwater control measures used to protect receiving water bodies. The TMDL program requires states to evaluate the condition of their water bodies, list those that do not meet water quality standards for their intended use, and develop a watershed management protocol for stakeholders (including MS4s) within the watershed for those water bodies that do not meet water quality standards. As such, MS4s are incentivized to manage stormwater in a cost-effective way that satisfies regulatory requirements and protects public health through effective stormwater control measures.

One way for MS4s to meet these objectives under the current regulatory framework is to leverage stormwater monitoring. For example, stormwater monitoring can be used to calibrate stormwater models, inform the development of TMDL load allocations, detect illicit discharges as defined by the NPDES, and demonstrate general compliance with permit provisions under both the NPDES and TMDL programs. However, because of the level of technical competence and capital needed to develop and maintain a stormwater discharge and water quality monitoring station, barriers to adoption are prevalent. Even so, many municipalities have recognized the value of such monitoring and have adopted continuous stormwater sampling as a response to regulations (City of Austin 2009; Jastram 2014; Hoogestraat 2015; Storms et al. 2015; Gauron 2015; Riddle 2016). For example, as a direct result of TMDLs set forth by the state, the city of Columbia, South Carolina, implemented a network of continuous in situ stormwater sampling sites to evaluate the water quality loads in their watersheds in order to influence their regulatory obligations using comprehensive monitoring data (Gauron 2015). In addition to these municipalities, there is a growing trend toward next-gen compliance as set forth by the USEPA, in which states and localities will seek to expand regulatory requirements to include advanced monitoring (Markell and Glicksman 2015). Therefore, it is important for MS4s to understand the value of continuous monitoring as it relates to the current and future regulatory environments.

Continuous stormwater monitoring stations, as defined in this study, are typically comprised of contemporary flow and water quality sensor technologies that can reliably and continuously collect flow and water quality samples of stormwater. Continuous flow measurement technologies include acoustic doppler velocimeters (ADV), acoustic doppler current profilers (ADCP), and water level sensors. Continuous water quality sampling technologies include in situ multiparameter Sondes that can collect water quality variables such as $\mathrm{pH}$, temperature, turbidity, dissolved oxygen, specific conductance, and oxidation reduction potential, among others. Other continuous water quality monitoring technologies include automated samplers that can take composite or discrete samples of stormflow using a time- 
weighted or volume-weighted sampling strategy. Automated samplers can be used to measure important regulatory water quality constituents such as total suspended solids (TSS) and phosphorous that can only be measured indirectly with surrogate parameters such as flow rate and turbidity by in situ sensors. Taken as a whole, these monitoring technologies can be used to effectively characterize water quality concerns relevant to MS4 regulatory compliance.

In light of growing science-based regulations to meet surface water quality standards (Bichai and Ashbolt 2017; Markell and Glicksman 2015), it is important to understand the value of high-frequency continuous monitoring for characterizing the health of streams. For example, if the timescale at which streamflow is measured is not adequately representative of rainfall-runoff processes, then this will result in uncertainty attributable to inadequate temporal sampling. This type of uncertainty can be categorized as epistemic uncertainty, defined as an inadequate knowledge of quantities that have a fixed value due to an inability to accurately measure or understand a system. Such uncertainty can result in incorrect conclusions about the health of a stream that could be avoided if sampling were done at a proper temporal scale. Therefore, it is important to quantify the uncertainty attributable to inadequate temporal sampling of stormflow and water quality constituents in order to optimize sampling strategies and avoid misrepresentative data.

Quantifying temporal sampling uncertainty can also highlight the value of continuous stormflow and water quality monitoring as an effective stormwater management tool that can accurately capture urban pollutant loads, anthropogenic pollutant events, and rainfall-runoff events that result in acutely toxic pollutant concentrations. A number of studies have demonstrated the utility of continuous watershed monitoring for TMDL calculations (Henjum et al. 2010; Gulati et al. 2014), capturing chloride runoff in urban streams (Corsi et al. 2010; Trowbridge et al. 2010), and monitoring other storm eventbased pollutant concerns (Ma et al. 2009; Wade et al. 2012; Jeong et al. 2012; Outram et al. 2014; Bieroza and Heathwaite 2015). However, there exists a need to further understand the effect that temporal sampling has on monitoring objectives, the uncertainty that is introduced when sampling intervals are inadequate to capture flow or water quality concerns, and the application of continuous monitoring for MS4 regulatory compliance.

This study seeks to address this gap by quantifying the uncertainty attributable to inadequate temporal sampling of stormflow and water quality constituents with respect to a range of MS4 monitoring objectives, and in doing so highlight the utility of continuous watershed monitoring as an effective stormwater management tool under current and future regulatory environments. To this end, the objectives of this study are to (1) evaluate uncertainty attributable to inadequate temporal sampling of stormwater discharge and water quality constituents through case studies of watersheds in Virginia at the scales of small urban catchments $\left(0.8-6.8 \mathrm{~km}^{2}\right)$ and large rural catchments $\left(30-16,000 \mathrm{~km}^{2}\right)$;

(2) determine the extent that this uncertainty may affect monitoring goals and objectives; and in doing so (3) demonstrate the value of continuous monitoring as an effective MS4 stormwater management tool.

\section{Methodology}

The methodology presented in this study evaluates the uncertainty attributable to inadequate temporal sampling of stormflow and water quality data; the effects that seasonality has on temporal uncertainty; and the subsequent effect of this uncertainty on capturing regulatory water quality constituents such as 
pollutant loads, illicit discharges, and acute pollutant toxicity. The methodology will be applied to case studies that include small urban and large rural watersheds to demonstrate the effects that scale has on uncertainty attributable to inadequate temporal sampling.

\section{Evaluating Uncertainty Attributable to Inadequate Temporal Sampling}

The uncertainty attributable to inadequate temporal sampling of stormflow and water quality during storm events is evaluated using the subsampling methodology defined below. Captured high-frequency stormflow hydrographs and water quality pollutographs are evaluated over a range of subsampled time intervals to assess how the subsampled time series effectively captures stormflow hydrograph characteristics such as runoff volume $(V)$, peak flow rate $\left(Q_{p}\right)$, and time to peak $\left(T_{p}\right)$, as well as water quality constituent characteristics such as mean $\left(C_{m}\right)$ and peak $\left(C_{p}\right)$ storm event concentrations.

The subsampling process involves taking a captured stormflow hydrograph or water quality pollutograph time series captured over a storm event and computing the storm characteristic of interest (i.e., runoff volume, peak flow rate, mean water quality constituent concentration, and so on). Then the time step of the captured time series $\left(t_{n}\right)$ is incrementally increased using the following equation:

$$
t_{n}=t_{0}+t_{0} \times n
$$

where $t_{0}=$ time step of the captured time series and $n=$ lag number. For each incremental time step or lag, the number of subsampled times series that can be simulated is equal to $n+1$, and each subsampled time series is created by shifting forward the point of time series initialization to

$$
x_{i}=x_{0}+(i-1) \times t_{0} \text {, for } i=1 \text { to } n+1
$$

where $i=$ ordinal number of subsampled time series $h(n, i)$ at lag $n ; x_{0}=$ time at the first point in the captured time series; and $x i=$ time at the first point in subsampled time series $h(n, i)$. For example, Fig. 1 represents two subsampled pollutographs, $h(1,1)$ and $h(1,2)$, developed from hypothetical data captured every $15 \mathrm{~min}\left(t_{0}\right)$. In this example, both pollutographs are developed using a time step of $30 \mathrm{~min}\left(t_{1}\right)$, where $h(1,1)$ is initialized at $x_{0}(0 \mathrm{~min})$ and $h(1,2)$ is initialized at $x_{1}(15 \mathrm{~min})$.

Once all possible subsampled time series are constructed for a given time lag, the characteristics of each subsampled time series are computed. These characteristics are then compared with the original captured characteristics to evaluate the uncertainty attributable to temporal sampling, defined as the average change in a stormflow time series characteristic at a time lag, and represented by $\overline{\Delta Y}$ in the following equation:

$$
{ }^{-} Y=\frac{1}{n+1} \sum_{\boldsymbol{d}_{i=1}}^{n+1} \frac{\left(\left|Y_{i}-Y_{0}\right|\right)}{Y_{0}}
$$

where $\overline{\Delta \mathrm{Y}}=$ average deviation in a time series characteristic (e.g., $V, Q_{p}, T_{p}$, and so on); $Y_{i}=$ value of a time series characteristic for the subsampled time series at step $i$; and $Y_{0}=$ value of a time series 
characteristic for the observed time series $(n=0)$. At each lag, Eq. (3) is used to compute $(\overline{\Delta Y})$ for all of the time series characteristics, and the process is repeated for consecutive lags $(n)$ until a maximum limit $\left(n_{\max }\right)$ is reached. Depending upon the captured sampling interval, and the definition of $n_{\max }$, the process can result in a large number of subsampled time series $\mathrm{h}(\mathrm{n}, \mathrm{i})$. For example, a captured 1-min time series (i.e., $\mathrm{t}_{0}=1 \mathrm{~min}$ ) evaluated up to a weekly sampling interval (i.e., $t_{n}=1$ week and $n_{\max }=1,079$ ) would result in the creation of 583,739 subsampled time series $h(n, i)$, with the number of subsampled time series created at each lag $(n)$ increasing linearly from 2 to 10,080 .

This process can be applied to a number of hydrographs or pollutographs at a single site, and a general linear regression model can be developed that predicts the uncertainty in a flow or water quality characteristic $(\overline{\Delta Y})$ as a function of the sampling interval, as represented in the following equation:

$$
\Delta Y=\beta_{0}+\beta_{1} * S I
$$

where $\beta 0$ and $\beta 1=$ regression constants and $S I=$ sampling interval in minutes. In many cases, the relationship between the response and predictor variables in Eq. (4) violates the least-squares regression assumption of homoscedasticity as the standard deviation in the residuals increases as a function of the fitted values. Therefore, response and predictor variables in Eq. (4) are transformed by log base 10 to meet the assumptions of least-squares regression. Additionally, where a plot of the residuals of the log-transformed data exhibits a nonnormal distribution or suggests a curvilinear relationship, polynomial terms of the predictor are added as appropriate. Therefore, Eq. (4) is modified as follows:

$$
\log (\Delta Y)=\beta_{0}+\beta_{1} * \log (S I)+\beta_{2} * \log (S I)^{2}+\cdots+\beta_{h} * \log (S I)^{h_{h}}
$$

where $h=$ degree of the polynomial. The outcome from Eq. (드) can then be applied to evaluate the uncertainty attributable to inadequate temporal sampling of different time-weighted sampling intervals at a site.

There are limitations to the methodology used to evaluate uncertainty attributable to inadequate temporal sampling as outlined in Eqs. (ㅌ)-(ㅁ). The methodology relies on flow and water quality data that are assumed to be sampled at frequencies fine enough to adequately capture hydrograph and pollutograph characteristics. The methodology also relies on the certainty of the measured stream discharge and water quality data, which can contain uncertainties from the sensors and measurement methods used (Aguilar et al. 2016; McMillan et al. 2012; Harmel et al. 2010). For example, Harmel et al. (2006) found that the cumulative uncertainty ranged from 6 to 19\% for streamflow measurements, 8$110 \%$ for total nitrogen and phosphorous loads, and $7-53 \%$ for TSS loads. The methodology also assumes that the storm events used at a given site are adequately representative of the expected storms within the watershed and are not biased by homogeneity in size, intensity, duration, and seasonality. 


\section{Evaluating Seasonal Differences}

It is well known that there are differences in hydrologic watershed functions between seasons because of changes in temperature, precipitation type, and land cover. To quantify the effect that these differences might have on uncertainty attributable to inadequate temporal sampling, the methodology is applied to a subset of storm event hydrographs, each representing different seasons, at representative small urban and large rural watersheds. This comparison can demonstrate how a stormflow sampling strategy might need to be modified to reflect seasonal influences on the hydrology of a watershed.

\section{Computing Pollutant Loads}

The uncertainties from stream discharge and water quality measurements during storm events can be combined together to quantify their cumulative effect on specific monitoring objectives. For example, storm event pollutant loads can be computed through a numeric integration of continuous flow and water quality data (Meals et al. 2013) as represented in the following equation:

\section{Pollutant Load $=\sum c_{i} Q_{i} \Delta t$}

where $C_{i}=$ concentration of the pollutant of interest at a specific time step; $Q_{i}=$ flow rate at a specific time step; and $\Delta t=$ time step increment. However, a common method to compute storm event pollutant loads is to simplify Eq. (ㅇ) to the following:

$$
\text { Pollutant Load }=C_{m} \times V
$$

where $C_{m}$ = average stormflow pollutant concentration and $V=$ stormflow volume, the uncertainties of which can be represented as $\overline{\Delta \mathrm{Cm}}$ and $\overline{\Delta \mathrm{V}}$ respectively. The two uncertainties from the average concentration of the pollutant and the volume of stormflow can be combined to get a comprehensive pollutant load uncertainty using the following equation:

$$
\overline{\Delta P L}=\sqrt{{\overline{\Delta C_{m}}}^{2}+\overline{\Delta V}^{2}}
$$

where $\overline{\Delta P L}=$ storm event pollutant load uncertainty. This pollutant load uncertainty can be evaluated over a combination of sampling intervals for $\overline{\Delta C_{m}}$ and $\overline{\Delta V}$, and then least-squares regression can be applied to develop a model predicting $\overline{\Delta P L}$ for a given water quality constituent within a watershed as a function of the sampling interval.

\section{Capturing Acute Toxicity Events and Illicit Discharges}

Another water quality event of concern occurs when pollutant concentrations exceed a threshold value for a short (acute) or long (chronic) period of time (USEPA 1986). An example is acute (1-h average) chloride toxicity, which occurs in watersheds as a result of road salt and deicing solutions that are applied in anticipation of winter storm events. These events are important for MS4s subject to snow and ice, as several states have set TMDL requirements on chloride concentrations in water bodies (Trowbridge et al. 2010). In addition, many MS4s are subject to high populations and impervious surfaces, making them high-risk contributors to acute chloride toxicity because of widespread road salt applications. 
In addition to water quality impairments that result from rainfall-runoff processes, many water quality impairments in urban streams occur as a result of anthropogenic activities, which can include illicit discharges, defined as an unauthorized discharge into a stormwater sewer system. Examples of illicit discharges include effluent from septic tanks, hosing down pollutants from roads and sidewalks, improper disposal of household liquids, sediment and pollutant runoff from construction sites, and anything else that is not stormwater or an authorized nonstormwater discharge. As part of meeting the NPDES permit requirements, many MS4s work to identify illicit discharges, often through outfall inspections by personnel who seek to capture illicit discharges either as they occur or afterward. However, another approach proposed in this study is to deploy in situ continuous flow and water quality monitoring in high-risk watersheds to capture and eliminate illicit discharges as they occur in real time.

To evaluate the uncertainty attributable to inadequate temporal sampling in capturing acute toxicity and illicit discharge events, Eq. ( $\underline{3})$ is applied to continuous water quality data at a single site during such events. The $\overline{\Delta Y}$ variables in this case are the mean concentration $\left(\overline{\Delta C_{m}}\right)$ and peak concentration $\left(\overline{\Delta C_{p}}\right)$ during an acute toxicity or illicit discharge event. Eq. (ㅁ) is then applied to the results to develop a regression relationship between $\overline{\Delta Y}$ and the sampling interval.

\section{Case Studies}

The case studies presented demonstrate the applicability of the methodology to evaluate uncertainty attributable to inadequate temporal sampling in both small urban and larger rural watersheds. There are a number of differences in the hydrologic processes that affect flow between urban and rural watersheds. The first is the presence of impervious surfaces in urban watersheds as a controlling variable in the generation of stormwater runoff volume and quality. Impervious surfaces remove the infiltration capacity of the watershed that may have existed in predevelopment conditions, resulting in quicker peak flows and larger volumes of runoff. In addition, impervious surfaces cause a number of water quality concerns including increased sediment, temperature, and other pollutants. Compounding this effect is the effect that piped and channelized flow paths in urban watersheds have on increasing the velocity of stormflow attributable to a loss of naturalized stream channels and flow paths. On the other hand, rural watersheds are strongly influenced by the land cover and soils that allow infiltration of precipitation, thereby producing less runoff than impervious surfaces found within urban areas.

Additionally, rural watersheds dominated by agricultural land uses may be subject to large degrees of sediment and pollutant runoff attributable to agricultural techniques and fertilizer use.

\section{Small Urban Watersheds}

The uncertainty attributable to inadequate temporal sampling was evaluated on small urban watersheds $\left(<10 \mathrm{~km}^{2}\right)$ for (1) discharge during storm events, (2) storm event pollutant concentrations and loads, (3) acute chloride toxicity from road-salt runoff, and (4) illicit discharges from anthropogenic activities. To meet these four objectives, this study applied the methodology to five urban watersheds within the town of Blacksburg, Virginia, and one urban watershed near the city of Fairfax, Virginia. The five sites within Blacksburg, Virginia, are referred to within this study as the Fire Station $\left(1.3 \mathrm{~km}^{2}\right)$, Main Street Inn $\left(0.8 \mathrm{~km}^{2}\right)$, Webb Street $\left(2.06 \mathrm{~km}^{2}\right)$, Roanoke Street $\left(1.96 \mathrm{~km}^{2}\right)$, and LEWAS $\left(2.7 \mathrm{~km}^{2}\right)$, and the location near Fairfax, Virginia, is referred to as Fairfax $\left(6.8 \mathrm{~km}^{2}\right)$. All six locations captured flow rate, while two of the locations (LEWAS and Fairfax) also captured continuous water quality constituents using in situ sensors. 
Uncertainty attributable to inadequate temporal sampling of stormflow was evaluated using data from all six urban sites. Four of the five sampling locations in Blacksburg captured stormflow data using an acoustic Doppler velocimeter (ADV) that provides a depth and one-dimensional velocity at differing sampling intervals of $1 \mathrm{~min}$ (Roanoke Street), $5 \mathrm{~min}$ (Fire Station), and $15 \mathrm{~min}$ (Webb Street and Roanoke Street). The other location within Blacksburg was the Learning Enhanced Watershed Assessment System (LEWAS) lab, an engineering education lab at Virginia Tech that uses an acoustic Doppler current profiler (ADCP) that provides a depth and a three-dimensional velocity captured every minute. The LEWAS is a real-time continuous watershed monitoring station that collects stormflow; water quality $(\mathrm{pH}$, dissolved oxygen, oxidation reduction potential, turbidity, temperature, and specific conductance); and weather (precipitation, wind speed, wind direction, air temperature, and relative humidity) data and broadcasts the data live through the online watershed learning system (OWLS) (McDonald et al. 2015; Brogan et al. 2016).

Uncertainty attributable to inadequate temporal sampling of water quality, such as pollutant loads, anthropogenic activities and and acute toxicity events, used data from the LEWAS and Fairfax sites. Continuous data form the LEWAS site was captured at 3-min intervals, and data form the Fairfax site (USGS Site 0156903) was captured 15 min intervals. TSS at the LEWAS site was estimated using a surrogate relationship established at the site between turbidity and TSS, and chloride was estimated from a surrogate relationship between specific conductance and chloride developed by a USGS study of urban streams in Virginia (Sanford et al. 2012). The Fairfax site estimated TSS and phosphorous using surrogate relationships established at the site with flow and turbidity as independent variables (Jastram 2014). While using surrogate parameters introduced additional uncertainties into the data, it allowed for an analysis of high-frequency continuous data sets over a number of storm events.

To evaluate the uncertainty in stormflow, pollutant concentrations, pollutant loads, acute chloride toxicity, and illicit discharges, eight events at each site were chosen for analysis. The number of events chosen for analysis was primarily driven by constraints on data availability, and while this may be a limitation of the methodology, efforts were taken to ensure that the storms represented a wide range of conditions that could be expected at the site. For example, the average coefficient of variation for the volume, peak flow, and time to peak across all sites was $1.07,0.83$, and 1.05 , respectively. In addition, for precipitation-based events, storms were selected over a relatively short time span (3 years) so as to not be heavily influenced by land cover or climatic changes.

\section{Large Rural Watersheds}

The second case study evaluated the uncertainty attributable to inadequate temporal sampling of large rural watersheds ( $>40 \mathrm{~km}^{2}$ ) for (1) discharge during storm events and (2) storm event pollutant concentrations and loads. The methodology was applied to six large rural watersheds within the state of Virginia that are monitored by the USGS (2017). The following six USGS sites (Fig. 2) chosen for analysis represent a range in drainage areas to facilitate comparisons attributable to scale: 02055100 Tinker Creek Near Daleville, Virginia (30 km²); 03177710 Bluestone River at Falls Mills, Virginia $\left(115 \mathrm{~km}^{2}\right)$; 01632900 Smith Creek Near New Market, Virginia (242 km²); 03475000 Holston River Near Meadowview, Virginia $\left(534 \mathrm{~km}^{2}\right) ; 01631000$ Shenandoah River at Front Royal, Virginia $\left(4,232 \mathrm{~km}^{2}\right)$; and 02035000 James River at Cartersville, Virginia $\left(16,192 \mathrm{~km}^{2}\right)$. All six sites capture flow rate and/or water quality constituents at 15-min sampling intervals. For each site, eight storms were chosen for analysis representing a range in duration and size, with an average coefficient of variation for stormflow volume, peak, and time to peak across all sites of $0.86,0.82$, and 0.38 , respectively. All six watersheds were 
evaluated for uncertainty attributable to inadequate temporal sampling of discharge during storm events, while pollutant load uncertainty was restricted to USGS sites 02035000 and 016329000 that capture flow rate as well as TSS. At both of these sites, TSS is estimated through a regression relationship with continuously measured turbidity and flow data as independent parameters (Hyer et al. $\underline{2015})$.

\section{Results and Discussion}

\section{Seasonal Differences in Stormflow Hydrographs}

The difference between seasonal hydrographs is illustrated in Fig. $\underline{3}$, which represents typical examples of hydrographs captured in the summer and winter at the Fire Station location. As illustrated, summer discharges typically have a sharp rising limb, a small crest, and a steep falling limb. Winter discharges also have a steep rising limb; however, they have an invariant peak location and crest, and a gradual falling limb. These differences in discharge characteristics can largely be attributed to the seasonal effects of temperature on the nature of rainfall-runoff processes in the urban environment. For example, during the summer months, precipitation in the form of liquid rain falls on the surface of Earth and quickly becomes runoff at the point of interception. On the other hand, during winter months, snow, sleet, or a wintry mix fall upon the land surface and slowly melt to become runoff at a rate dependent on the land surface temperature and salt application, among other factors.

To assess the effect that seasonal effects have on the uncertainty attributable to inadequate temporal sampling of stormflow, a case study evaluated six winter storms and five summer storms captured by the Fire Station stream gauge. The methodology to evaluate uncertainty attributable to inadequate temporal sampling of stormflow in regards to volume $(\overline{\Delta V})$, peak flow rate $\left(\overline{\Delta Q_{p}}\right)$, and the time to peak $\left(\overline{\Delta T_{p}}\right)$, was performed on all 11 storms and plotted together in Fig. $\underline{4}$. Fig. $\underline{4}$ represents three plots of the uncertainty attributable to inadequate temporal sampling of hydrograph characteristics (e.g., $\overline{\Delta V}$, $\left(\overline{\Delta Q_{p}}\right)$, and $\left(\overline{\Delta T_{p}}\right)$ derived from Eq. ( $\left.\underline{3}\right)$ as a function of the sampling interval. Each trend in the data represents a different storm and the gray scale represents the month of the year, which is also indicative of the season during which the stormflow was captured. As illustrated, storms that occur during winter months and that are more likely to be dominated by snowfall (as represented by the darker data points) generally exhibit a lower uncertainty than those that are likely to be dominated by rainfall. This pattern is further demonstrated by applying Eq. (ㅁ) to the overall data sets in Fig. $\underline{4}$, as well as subsets of summer and winter storms. These results are summarized in Table $\underline{1}$, which shows that the sampling intervals associated with magnitudes of $\overline{(Y}$ ) are generally lower for summer storms than for winter storms.

Table 1. Uncertainty Sampling Intervals ( $\mathrm{min}$ ) for Analysis of All, Summer, and Winter Storms for the Fire Station Site in Blacksburg, Virginia

\begin{tabular}{|l|l|l|l|l|l|l|l|l|l|}
\hline $\begin{array}{l}\text { Uncertainty \% } \\
(\overline{\Delta Y})\end{array}$ & Volume & & & $\begin{array}{l}\text { Peak } \\
\text { flow }\end{array}$ & & & $\begin{array}{l}\text { Time to } \\
\text { peak }\end{array}$ & & \\
\hline & All & Summer & Winter & All & Summer & Winter & All & Summer & Winter \\
\hline 2.5 & 15 & 15 & 13 & 5 & 5 & 6 & 8 & 8 & 9 \\
\hline
\end{tabular}




\begin{tabular}{|l|l|l|l|l|l|l|l|l|l|}
\hline 5 & 28 & 23 & 43 & 9 & 8 & 12 & 9 & 8 & 12 \\
\hline 10 & 55 & 39 & 95 & 18 & 14 & 25 & 12 & 10 & 18 \\
\hline 20 & 109 & 73 & 179 & 40 & 29 & 62 & 18 & 14 & 31 \\
\hline 30 & 166 & 109 & 249 & 70 & 47 & 124 & 24 & 17 & 43 \\
\hline
\end{tabular}

Because of the effect that seasonality has on precipitation-runoff processes, the uncertainty attributable to inadequate temporal sampling of stormflow and storm event pollutant concentrations and loads was restricted to rainfall-dominated storms captured during summer months. While this does not capture hydrograph responses during winter events, it produces a conservative estimate of $\overline{\Delta Y}$, because it can be assumed that on average rainfall-only storms will result in a larger deviation of $\overline{\Delta Y}$ than that of storms influenced by winter precipitation. In regards to the remaining objectives, road-salt runoff events were restricted to winter storms when deicing occurs; however, illicit discharge events were not restricted by season because they are independent of precipitation.

In addition, there was a seasonal influence on the values of $\overline{\Delta Y}$ between summer and winter storms for large rural watersheds. This influence is illustrated in Table $\underline{2}$, which summarizes the results of applying Eq. (ㅁ) to all storms, summer storms, and winter storms. Since seasonal influences in this study have a similar effect on rural watersheds as they do on urban watersheds, the uncertainty attributable to inadequate temporal sampling of discharge during storm events and storm event pollutant concentrations and loads was restricted to rainfall-dominated storms captured during summer months. Therefore, as in the case of the urban watersheds, this will be a conservative estimate of the effect that sampling frequency has on hydrograph characteristics.

Table 2. Uncertainty Sampling Intervals ( $\mathrm{min}$ ) for Analysis of All, Summer, and Winter Storms for USGS Site 02055000

\begin{tabular}{|l|l|l|l|l|l|l|l|l|l|}
\hline $\begin{array}{l}\text { Uncertainty \% } \\
(\overline{\Delta Y})\end{array}$ & Volume & & & $\begin{array}{l}\text { Peak } \\
\text { flow }\end{array}$ & & & $\begin{array}{l}\text { Time } \\
\text { to } \\
\text { peak }\end{array}$ & & \\
\hline & All & Summer & Winter & All & Summer & Winter & All & Summer & Winter \\
\hline 2.5 & 164 & 122 & 819 & 56 & 44 & 466 & 53 & 55 & 34 \\
\hline 5 & 245 & 185 & 1,313 & 88 & 63 & 692 & 63 & 62 & 74 \\
\hline 10 & 374 & 280 & 1,594 & 157 & 104 & 1,081 & 82 & 75 & 154 \\
\hline 20 & 603 & 435 & 1,841 & 319 & 194 & 1,854 & 122 & 101 & 314 \\
\hline 30 & 868 & 579 & 1,989 & 529 & 299 & 2,482 & 161 & 128 & 474 \\
\hline
\end{tabular}

Urban Watersheds

\section{Stormflow}

The analysis of uncertainty attributable to inadequate temporal sampling of stormflow was conducted on eight storms at each site, and Eq. ( $\underline{5}$ ) was applied to the data to develop a least-squares regression model. An example of the outcome from the analysis of eight storms on the LEWAS site is illustrated in Fig. $\underline{5}$. This represents the uncertainty in volume $(\overline{\Delta V})$, peak flow rate $\left(\overline{\Delta Q_{p}}\right)$, and time to peak $\left(\overline{\Delta T_{p}}\right)$ as a function of the sampling interval. The outcome of this model, and those developed at the other five 
urban watershed sites, is summarized in Table $\underline{3}$, which provides the sampling intervals at each site associated with a specific level of uncertainty. The sampling intervals are generally lowest for time to peak, followed by peak flow rate and volume. This can be expected as the time to peak and peak flow rate are single variable functions with fixed maximum (peak flow rate) or minimum (time to peak) values. However, volume is a product of both flowrate and time, where the time interval increases with each lag, while the chances of capturing the maximum flow rate decrease. The table highlights the need for continuous monitoring to effectively capture important hydrograph characteristics during storm events, which is especially important if using flow monitoring to evaluate program effectiveness or BMP performance. This uncertainty also has further implications for storm event water quality concerns as discussed in the following sections.

Table 3. Urban Watershed Sampling Intervals ( $\min$ ) for Volume, Peak, and Time to Peak Uncertainty Thresholds

\begin{tabular}{|l|l|l|l|l|l|l|l|l|l|}
\hline Site & Volume & & & Peak & & & Time to Peak & & \\
\hline & $\mathbf{2 . 5 \%}$ & $\mathbf{1 0} \%$ & $\mathbf{3 0} \%$ & $\mathbf{2 . 5 \%}$ & $\mathbf{1 0 \%}$ & $\mathbf{3 0 \%}$ & $\mathbf{2 . 5 \%}$ & $\mathbf{1 0 \%}$ & $\mathbf{3 0 \%}$ \\
\hline Fairfax & 53 & 109 & 278 & 6 & 42 & 154 & 45 & 51 & 65 \\
\hline FS & 15 & 38 & 106 & 5 & 14 & 50 & 6 & 11 & 17 \\
\hline LEWAS & 11 & 20 & 44 & 3 & 10 & 32 & 11 & 13 & 16 \\
\hline MSI & 22 & 50 & 96 & 7 & 21 & 62 & 6 & 10 & 21 \\
\hline RS & 6 & 15 & 42 & 5 & 8 & 21 & 3 & 4 & 7 \\
\hline WS & 23 & 38 & 78 & 10 & 23 & 64 & 12 & 15 & 23 \\
\hline
\end{tabular}

Taken together, the uncertainties attributable to inadequate temporal sampling of stormflow and water quality constituents can be combined together to evaluate how they affect important watershed concerns such as stormflow pollutant loads. This is illustrated in Fig. $\underline{6}$, which shows the combined pollutant load uncertainty as a function of the sampling interval for TSS (LEWAS and Fairfax) and phosphorous (Fairfax) pollutant loadings.

One application of these data is to use them to derive a continuous time-weighted monitoring strategy where stormflow pollutant loads are a primary monitoring objective. For example, Fig. $6(\mathrm{a})$ is annotated to represent the case where a sampling strategy seeks to continuously monitor flow and water quality (TSS) at the LEWAS site while restricting the pollutant load uncertainty attributable to inadequate temporal sampling to $10 \%$. In this case, the black solid lines in Fig. 6(a) indicate that the sampling interval would need to be less than or equal to $17 \mathrm{~min}$, which could be applied to a continuous in situ Sonde measurement or time-weighted automated sampler. However, this assumes that the flow and water quality are sampled at the same time interval, which is not always the case. Fortunately, Eq. (으) allows flexibility in evaluating the pollutant load uncertainty for any combination of flow and water quality sampling intervals. 
These results also demonstrate the necessity of continuous monitoring for accurately evaluating pollutant concentrations and loads during storm events in urban watersheds. This type of monitoring could be useful for MS4s in calibrating runoff models, demonstrating BMP performance, evaluating regulatory compliance of pollutant loads, and informing TMDL regulations. Other water quality sampling strategies that are not continuous, such as grab samples at daily or weekly intervals, would clearly introduce a large degree of uncertainty based upon these results. For example, daily grab sampling at the Fairfax site would introduce 29-94\% uncertainty in storm event mean concentrations and 93-129\% uncertainty in stormflow pollutant loads.

\section{Road-Salt Runoff}

The uncertainty attributable to inadequate temporal sampling was also applied to acute chloride toxicity events from road-salt runoff captured at the LEWAS site. Road-salt events were evaluated for the deviation in mean concentration above the acute toxicity threshold of $840 \mathrm{mg} / \mathrm{L}\left(\overline{\Delta C_{m}}\right)$ and the peak concentration $\left(\overline{\Delta C_{p}}\right)$. An example of an acute chloride toxicity event is illustrated in Fig. $\underline{7}$, which shows the estimated chloride concentration as well as the EPA recommended limit. As illustrated, the estimated chloride concentration significantly exceeds the EPA recommended threshold during this runoff event.

The uncertianty attributable to inadequate temporal sampling of the mean concentration and peak concentration for acute chloride toxicity was performed on eight events, with an average duration of exceedance of $5.9 \mathrm{~h}$. The models developed by applying Eq. (ㅁ) to the uncertainty data are provided in Table $\underline{4}$. Applying the equations in Table 4 , the sampling interval required for a given degree of mean concentration uncertainty is greater for capturing chloride than TSS at the LEWAS site (e.g., 75 min for chloride and $32 \mathrm{~min}$ for TSS at $0.1 \overline{\Delta C_{m}}$ ). In addition, chloride also has a poorer model fit across $\overline{\Delta C_{m}}$ ) and $\overline{\Delta C_{p}}$ ). The difference in sampling intervals may be attributable to the fact that winter precipitationrunoff processes in urban watersheds are more complex because of precipitation melt and runoff facilitated by road salts at the point of interception as demonstrated previously in Fig. $\underline{3}$. The lack of model fit may be attributable to the heterogeneous concentration of road salts within the watershed across storm events, which are dependent upon the location and application rate by public works and facilities workers.

Despite variation among storm events, these results demonstrate the necessity of continuous sampling for capturing road-salt effects on chloride concentrations in water bodies. For example, whereas current TMDLs may recommend sampling at monthly or at most biweekly intervals (Henjum et al. 2010; MPCA 2004), it is clear that for similar urban watersheds, this sampling interval would miss the effect of road salts on the chloride concentration in a water body (e.g., $82 \% \overline{\Delta C_{m}}$ ) and $83 \% \overline{\Delta C_{p}}$ ) for daily sampling). Therefore, such applications could benefit from continuous monitoring of surrogate variables in lieu of or in addition to monthly or weekly chloride sampling.

\section{Illicit Discharge Analysis}

The uncertainty attributable to inadequate temporal sampling in capturing illicit discharges was evaluated for dry-weather events captured at the LEWAS site where the $\mathrm{pH}$ exceeded the EPA recommended limits of 6.5-9 for freshwater bodies (USEPA 1986). An example of these events is illustrated in Fig. $\underline{8}$, which shows both high and low pH exceedance events captured at the LEWAS site 
during July 2013 and October 2014. It is hypothesized that the illicit discharges were the result of construction activities within the watershed, although this is merely speculative since the exact cause could not be confirmed.

The analysis of uncertainty attributable to inadequate temporal sampling was performed on eight highexceedance and eight low-exceedance events, with an average duration of exceedance for the high- and low-pH events of 2.9 and $2.2 \mathrm{~h}$, respectively. Then a model was fit to the uncertainty in mean and peak concentration as a function of the sampling interval, as shown in Table $\underline{4}$. The sampling interval for a given degree of mean pollutant concentration uncertainty was larger for high-pH events than for low-pH events (e.g., 129 and $32 \mathrm{~min}$, respectively, at $0.1 \overline{\Delta C_{m}}$ ). This can most likely be attributed to the unpredictable nature of illicit discharges, which are independent from rainfall-runoff processes and largely dependent upon anthropogenic forces.

The high levels of uncertainty further demonstrate that continuous monitoring is a valuable tool for detection and elimination of illicit discharges, one of the six minimum control measures outlined by the NPDES. If using the traditional method of illicit discharge detection through physical inspections, a site would have to be inspected during the 1-5 $\mathrm{h}$ that the illicit discharge is detectable-an unlikely event, given that illicit discharge detections are usually performed on an annual basis. However, continuous monitoring can detect the illicit discharges and alert appropriate stormwater program operators in real time. For example, in the time since the capture of these events, the LEWAS has been updated to send alerts in real time to MS4 operators within the watershed when water quality constituents exceed threshold limits, leading to the successful detection and elimination of illicit discharges.

\section{Rural Watersheds}

Stormflow

The uncertainty attributable to inadequate temporal sampling of stormflow was applied to six large rural watershed locations. The results are summarized in Table $\underline{5}$, which contains the sampling interval for volume, peak, and time to peak at specific uncertainty thresholds. Just as with the urban watersheds, the sampling intervals are generally lowest for time to peak and highest for volume.

Table 5. Rural Watershed Sampling Intervals (min) for Volume, Peak, and Time to Peak Uncertainty Thresholds

\begin{tabular}{|l|l|l|l|l|l|l|l|l|l|}
\hline USGS site & Volume & & & Peak & & & Time to peak & & \\
\hline & $\mathbf{2 . 5 \%}$ & $\mathbf{1 0 \%}$ & $\mathbf{3 0 \%}$ & $\mathbf{2 . 5 \%}$ & $\mathbf{1 0 \%}$ & $\mathbf{3 0 \%}$ & $\mathbf{2 . 5 \%}$ & $\mathbf{1 0 \%}$ & $\mathbf{3 0 \%}$ \\
\hline 1631000 & 1,036 & 2,596 & 5,007 & 589 & 1,538 & 3,080 & 73 & $\mathbf{2 0 5}$ & 555 \\
\hline 1632900 & 320 & 750 & 1,695 & 120 & 345 & 1,055 & 185 & 250 & 421 \\
\hline 2035000 & 1,290 & 2,745 & 5,385 & 735 & 1,605 & 4,275 & 510 & 693 & 1,179 \\
\hline 2055100 & 65 & 138 & 355 & 25 & 58 & 171 & 50 & 59 & 85 \\
\hline 3177710 & 68 & 185 & 550 & 27 & 73 & 228 & 55 & 73 & 122 \\
\hline 3475000 & 650 & 1,381 & 2,445 & 222 & 636 & 1,654 & 59 & 170 & 464 \\
\hline
\end{tabular}




\section{Storm Event Pollutant Concentrations and Loads}

Fig. $\underline{9}$ illustrates the uncertainty in pollutant loads as a function of the sampling interval for two USGS sampling locations. The effect of basin size between these two sites is evident in the scale of the $X$-axis (SI); however, both of the sites follow similar trends. At both sites the uncertainty in suspended solids concentrations is similar in magnitude to the uncertainty in stormwater discharge volume, possibly because of the use of flow as an independent variable in the estimation of TSS. However, this could also suggest that the uncertainty in stormflow volume is a good indicator for predicting the uncertainty in mean suspended solids concentration as a function of sampling interval for large rural watersheds.

These results further demonstrate the value of continuous monitoring for larger watersheds. For example, many TMDLs developed for larger streams such as those evaluated in this case study use daily or weekly sampling intervals (Henjum et al. 2010; MPCA 2004). However, even daily sampling would introduce an uncertainty in capturing the storm event mean concentration of 10 and $20 \%$ and storm event pollutant load of 10 and $28 \%$ for Sites 02035000 and 01632900 , respectively. This uncertainty in turn would directly affect the estimation of daily, weekly, monthly, or yearly pollutant loads as set forth by TMDL regulations. While MS4s will be most interested in monitoring what they directly contribute to a water body, such as municipal outfalls that capture small urban watersheds, monitoring on a larger scale could complement outfall monitoring to evaluate the watershed-level effects that a MS4 has on flow and water quality-the overarching objective of TMDL and NPDES regulations.

\section{Implications for Various Sampling Methods}

While the data within this study were restricted to in situ sensors, continuous monitoring of water quality parameters can take a number of forms depending upon the available resources, site restrictions, and monitoring objectives. For example, in the case of precipitation-driven events, continuous monitoring of water quality could include in situ water quality Sondes, automated timeweighted discrete samplers, and automated flow-weighted discrete or composite samplers. The methodology presented in this paper is directly applicable to in situ and time-weighted monitoring; however, it does not directly address automated flow-weighted samplers, which collect samples at incremental stormflow volumes.

To assess a sampling strategy for flow-weighted automated samplers, the methodology could be modified to evaluate uncertainty attributable to inadequate volumetric sampling. Flow-weighted sampling assumes that each sample is representative of the average pollutant concentration for the volume increment to which it corresponds. If the volume increment is too large and the pollutant concentration changes rapidly, the measured pollutant concentration may not accurately represent the average pollutant concentration in the volume. On the other hand, if the volume increment is too small, it may require collecting more samples than the typical 4-94 samples that an automated sampler can hold. Consequently, flow-weighted sampling requires knowledge of the rainfall-runoff dynamics of a watershed to select a flow increment that considers both the need for pollutant load accuracy and the number or cost of samples taken. It therefore would benefit from an analysis of empirical data that defines the uncertainty attributable to inadequate volumetric sampling at a site. In such an analysis, the time steps and sampling intervals within Eqs. (י)-(ㅁ) would instead relate to the incremental sampling volumes. Using this approach, an analysis could choose a trigger volume or volumetric sample increment based upon an acceptable level of uncertainty. Such an analysis would be especially helpful in studies 
that evaluate the event mean concentration, which are largely performed using flow-weighted sampling.

In addition, this methodology could also provide insights into the uncertainties attributable to inadequate temporal sampling of automated samplers that employ a user-defined sampling strategy. For example, the most rapid change in pollutant concentration will occur at the beginning of the storm event. Therefore, a user-defined sampling strategy could collect in higher frequencies on the rising limb and lower frequencies on the falling limb in order to reduce uncertainties, minimize cost, and maximize the efficiency of the limited number of samples within an automated sampler. Although this methodology does not address user-defined sampling directly, one way to use the data could be to select a lower uncertainty threshold for the rising limb and a greater uncertainty threshold for the falling limb. For example, to capture peak and mean concentrations, a sampling strategy could use the sampling interval associated with capturing the peak concentration $\left(\overline{\Delta C_{p}}\right)$ at the beginning of the runoff event and the interval associated with capturing the mean concentration $\left(\overline{\Delta C_{m}}\right)$ once runoff begins to recede.

When developing a stormwater monitoring plan, it is also important to understand the advantages and disadvantages of various water quality sampling methods as they pertain to specific monitoring objectives. For example, in the case of automated samplers, the advantages of flow-weighted sampling are that it can collect discrete or composite samples, the latter of which only requires the analysis of one sample per storm event to develop an event mean concentration. Alternatively, time-weighted sampling is restricted to collecting discrete samples, which may be cost-prohibitive for automated samplers that require a laboratory analysis of each sample. Disadvantages of automated samplers are that they cannot be deployed for continuous measurements over long periods of time because of the restricted number of samples that they can hold, are unable to measure and transmit data in real time, and only collect samples after a detectable increase in flow or precipitation. Consequently, automated samplers would be infeasible for the detection of illicit discharges, which usually do not cause a detectable increase in flow. In the case of in situ sensors, there are a number of advantages since they do not have a significant cost associated with each sample collected, are not restricted by the number of samples that they can collect, can be continuously deployed over long periods of time, and can measure and transmit data in real time. However, disadvantages of in situ sensors are that they cannot directly measure many water quality constituents of regulatory concern, such as TSS and phosphorous, with the accuracy of automated samplers, and in many cases require the use of surrogate parameters.

\section{Conclusions}

This study has demonstrated the utility of continuous flow and water quality monitoring as an effective MS4 management tool through the evaluation of uncertainty attributable to inadequate temporal sampling of flow and water quality constituents. In light of regulatory requirements under both the NPDES and TMDL programs, there are a number of applications for continuous monitoring in managing stormwater at the municipal scale. The results from this study also demonstrate that continuous monitoring is useful and in some cases necessary for accurately capturing storm event pollutant loads, illicit discharges, and acute toxicity in small urban watersheds. As regulatory requirements begin to leverage advanced monitoring techniques (Markell and Glicksman 2015), more municipalities will be incentivized to adopt continuous monitoring practices. As such, unique solutions to urban stormwater 
management exist at the intersection of increasing regulatory pressures and improvements in costeffective monitoring technologies.

To that end, as municipalities adapt to changing regulations, such as the recent modifications to the NPDES rules requiring stricter permit review and greater public engagement for small MS4s (USEPA 2016), there may be cost-effective ways to deploy continuous monitoring for meeting multiple regulatory objectives. For example, NPDES permits require MS4s to develop a stormwater management program that addresses construction site runoff control, illicit discharge detection and elimination, pollution prevention, postconstruction runoff control, public education and outreach, public involvement/participation, program effectiveness, and total maximum daily loads. As demonstrated, continuous monitoring can be used to meet multiple objectives under this framework. For example, continuous monitoring can be applied to (1) demonstrate program effectiveness, construction and postconstruction site runoff BMP performance, pollution prevention effectiveness, and adherence to TMDL regulations; (2) capture and eliminate illicit discharges in real time; and (3) provide public education and outreach through public access to and communication of monitoring data. An understanding of the multiple benefits of continuous monitoring can help to break down barriers to the adoption of capital-intensive stormwater monitoring sites.

The methodology presented within this study to evaluate the uncertainty attributable to inadequate temporal sampling of stormflow could be modified to assess volume-weighted and user-defined sampling or applied to other types of time series. For example, other water quality constituents of interest such as metals, bacteria, or other pollutants not addressed in this study may exhibit different temporal concentration characteristics in watersheds for which this methodology could be applied. In addition, the methodology could be applied to other hydrologic time series such as groundwater, lake, or reservoir flow and water quality to evaluate how the uncertainty attributable to inadequate temporal sampling affects their relevant monitoring objectives. While this study looks at temporal scales at a single location, future work could also examine how the combined spatial distribution and time scales of monitoring stations affect uncertainties within a watershed. In addition, wide-scale adoption of continuous monitoring that results in large complex datasets could provide opportunities for data analytic and data visualization techniques that support runoff management and real-time controls of stormwater systems (Kerkez et al. 2016). Ultimately, as watershed monitoring increases in adoption and scale, research is needed to understand the relevant temporal scales of runoff processes, the applications for big data that wide-scale monitoring will produce, and the best practices to meet monitoring objectives.

\section{References}

Aguilar, M. F., McDonald, W. M., and Dymond, R. L. (2016). "Benchmarking laboratory observation uncertainty for in-pipe storm sewer discharge measurements." J. Hydrol., 534, 73-86.

Bichai, F., and Ashbolt, N. (2017). "Public health and water quality management in low-exposure stormwater schemes: A critical review of regulatory frameworks and path forward." Sustainable Cities Soc., 28 , 453-465.

Bieroza, M. Z., and Heathwaite, A. L. (2015). "Seasonal variation in phosphorus concentration-discharge hysteresis inferred from high-frequency in situ monitoring." J. Hydrol., 524, 333-347.

Brogan, D. S., McDonald, W. M., Lohani, V. K., and Dymond, R. L. (2016). "A high-frequency real-time system for creating and sharing environmental data." Adv. Eng. Educ., 5(2), in press. 
City of Austin. (2009). "Stormwater runoff quality and quantity from small watersheds in Austin, TX: Updated through 2008." Rep. No. CM-09-03, Austin, TX.

Corsi, S. R., Graczyk, D. J., Geis, S. W., Booth, N. L., and Richards, K. D. (2010). "A fresh look at road salt: Aquatic toxicity and water-quality impacts on local, regional, and national scales." Environ. Sci. Technol., $\underline{44}(\underline{19})$, 7376-7382.

Gauron, T. (2015). "State promulgates TMDLs based on sporadic grab sampling." World Water Stormwater Manage., 3(3), 19-21.

Gulati, S., Stubblefield, A. A., Hanlon, J. S., Spier, C. L., and Stringfellow, W. T. (2014). "Use of continuous and grab sample data for calculating total maximum daily load (TMDL) in agricultural watersheds." Chemosphere, $\underline{99}, 81-88$.

Harmel, R. D., Cooper, R. J., Slade, R. M., Haney, R. L., and Arnold, J. G. (2006). "Cumulative uncertainty in measured streamflow and water quality data for small watersheds." Trans. ASABE, $\underline{49}(\underline{3})$, 689-701.

Harmel, R. D., Slade, R. M., and Haney, R. L. (2010). "Impact of sampling techniques on measured stormwater quality data for small streams." J. Environ. Qual., 39 $(\underline{5}), 1734-1742$.

Henjum, M. B., Hozalski, R. M., Wennen, C. R., Novak, P. J., and Arnold, W. A. (2010). "A comparison of total maximum daily load (TMDL) calculations in urban streams using near real-time and periodic sampling data." J. Environ. Monit., 12(1) $)$ 234-241.

Hoogestraat, G. K. (2015). "Water-quality characteristics of stormwater runoff in Rapid City, South Dakota, 2008-14." Scientific Investigations Rep. No. 2015-5069, U.S. Geological Survey, Reston, VA.

Hyer, K., Jastram, J. D., Moyer, D., Webber, J. S., and Chanat, J. G. (2015). "Evaluation and application of regional turbidity-sediment regression models in Virginia." 10th Federal Interagency Sedimentation Conf., U.S. Geological Survey, Reston, VA.

Jastram, J. D. (2014). "Streamflow, water quality, and aquatic macroinvertebrates of selected streams in Fairfax County, Virginia, 2007-12." Scientific Investigations Rep. No. 2014-5073, U.S. Geological Survey, Reston, VA.

Jeong, J. J., et al. (2012). "Differential storm responses of dissolved and particulate organic carbon in a mountainous headwater stream, investigated by high-frequency, in situ optical measurements." J. Geophys. Res. Biogeosci., 117(G3), G03013.

Kerkez, B., et al. (2016). "Smarter stormwater systems." Environ. Sci. Technol., 50 (14), 7267-7273.

Ma, J. S., Kang, J. H., Kayhanian, M., and Stenstrom, M. K. (2009). "Sampling issues in urban runoff monitoring programs: Composite versus grab." J. Environ. Eng., 10.1061/(ASCE)07339372(2009)135:3(118), 118-127.

Markell, D., and Glicksman, R. (2015). "Next generation compliance." 〈https://ssrn.com/abstract=2662105), (Oct. 11, 2017).

McDonald, W. M., Brogan, D. S., Lohani, V. K., Dymond, R. L., and Clark, R. L. (2015). "Integrating a realtime environmental monitoring lab into university and community college courses." Int. J. Eng. Educ., 31(4), 1139-1157.

McMillan, H., Krueger, T., and Freer, J. (2012). "Benchmarking observational uncertainties for hydrology: Rainfall, river discharge and water quality." Hydrol. Processes, 26 (26)

Meals, D. W., Richards, R. P., and Dressing, S. A. (2013). "Pollutant load estimation for water quality monitoring projects." National Nonpoint Source Monitoring Program, Tech Notes 8, U.S. Environmental Protection Agency, Tetra Tech, Inc., Fairfax, VA. 
MPCA (Minnesota Pollution Control Agency). (2004). "Minnesota's water quality monitoring strategy 2004 to 2014: A report prepared for the U.S. Environmental Protection Agency." 〈https://www.leg.state.mn.us/docs/2009/other/090504.pdf) (Oct. 11, 2017).

Outram, F. N., et al. (2014). "High-frequency monitoring of nitrogen and phosphorus response in three rural catchments to the end of the 2011-2012 drought in England." Hydrol. Earth Syst. Sci., $\underline{18}(\underline{9}), 3429-3448$.

Riddle, J. H. (2016). “Monitoring to mitigate TMDL trauma." Proc. Water Environ. Fed., 2016() 4440.

Sanford, W. E., Nelms, D. L., Pope, J. P., and Selnick, D. L. (2012). “Quantifying components of the hydrologic cycle in Virginia using chemical hydrograph separation and multiple regression analysis." U.S. Geological Survey Scientific Investigations Rep. No. 2011-5198, U.S. Geological Survey, Reston, VA, 152.

Storms, E. F., Oelsner, G. P., Locke, E. A., Stevens, M. R., and Romero, O. C. (2015). "Summary of urban stormwater quality in Albuquerque, New Mexico 2003-12." Scientific Investigations Rep. No. 2015-5006, U.S. Geological Survey, Reston, VA.

Trowbridge, P. R., Kahl, J. S., Sassan, D. A., Heath, D. L., and Walsh, E. M. (2010). "Relating road salt to exceedances of the water quality standard for chloride in New Hampshire streams." Environ. Sci. Technol., 44 (13), 4903-4909.

USEPA (United States Environmental Protection Agency). (1986). "Quality criteria for water." EPA 440/586-001, Washington, DC.

USEPA (United States Environmental Protection Agency). (2016). "National pollutant discharge elimination system (NPDES) municipal separate storm sewer system general permit remand rule, 40 CFR Part 122." 〈https://www.gpo.gov/fdsys/pkg/FR-2016-12-09/pdf/2016-28426.pdf) (Oct. 11, 2017).

USGS. (2017). "Real-time water data for the nation." 〈http://waterdata.usgs.gov/nwis/rt (Feb. 2017).

Wade, A. J., et al. (2012). "Hydrochemical processes in lowland rivers: Insights from in situ, highresolution monitoring." Hydrol. Earth Syst. Sci., 16 $\underline{\text { 11) }}$, 4323-4342. 